\title{
Trends in educational inequalities in obesity in 15 European countries between 1990 and 2010
}

\author{
Kristina Hoffmann ${ }^{1,2}$, Rianne De Gelder ${ }^{1}$, Yannan Hu' ${ }^{1}$, Matthias Bopp ${ }^{3}$, Jozsef Vitrai ${ }^{4}$, Eero Lahelma ${ }^{5}$, \\ Gwenn Menvielle ${ }^{6}$, Paula Santana ${ }^{7}$, Enrique Regidor ${ }^{8}$, Ola Ekholm ${ }^{9}$, Johan P. Mackenbach ${ }^{1}$ \\ and Frank J. van Lenthe ${ }^{1 *}$
}

\begin{abstract}
Background: The prevalence of obesity increased dramatically in many European countries in the past decades. Whether the increase occurred to the same extent in all socioeconomic groups is less known. We systematically assessed and compared the trends in educational inequalities in obesity in 15 different European countries between 1990 and 2010.

Methods: Nationally representative survey data from 15 European countries were harmonized and used in a metaregression of trends in prevalence and educational inequalities in obesity between 1990 and 2010. Educational inequalities were estimated by means of absolute rate differences and relative rate ratios in men and women aged 30-64 years.

Results: A statistically significant increase in the prevalence of obesity was found for all countries, except for Ireland (among men) and for France, Hungary, Italy and Poland (among women). Meta-regressions showed a statistically significant overall increase in absolute inequalities of $0.11 \%$ points $[95 \% \mathrm{Cl} 0.03,0.20]$ per year among men and $0.12 \%$ points $[95 \% \mathrm{Cl} 0.04,0.20]$ per year among women. Relative inequalities did not significantly change over time in most countries. A significant reduction of relative inequalities was found among Austrian and Italian women.

Conclusion: The increase in the overall prevalence aligned with a widening of absolute but not of relative inequalities in obesity in many European countries over the past two decades. Our findings urge for a further understanding of the drivers of the increase in obesity in lower education groups particularly, and an equity perspective in population-based obesity prevention strategies.
\end{abstract}

Keywords: Health inequalities, Obesity, Time trends

\section{Background}

Socioeconomic inequalities in mortality and selfreported morbidity have been extensively documented in national and international studies [1-7]. For both of these outcomes, and either defined by educational or income level, rates are higher in the lower socioeconomic groups. Patterns of inequality are, however, not static: a larger absolute decline in mortality rates in lower as compared to higher socioeconomic groups, has resulted

\footnotetext{
* Correspondence: f.vanlenthe@erasmusmc.nl

'Department of Public Health, Erasmus MC, University Medical Center Rotterdam, P.O. Box 2040, 3000 CA Rotterdam, Netherlands

Full list of author information is available at the end of the article
}

in a narrowing of the difference in mortality rates between low and high socioeconomic groups (i.e., a decline in absolute inequalities) in many European countries over the past two decades. At the same time, the larger decline in the low as compared to the high socioeconomic group increased the ratio of mortality in the lower as compared to the higher socioeconomic group (i.e., an increase in relative inequality) [8]. Thus, it is important to consider both absolute and relative measures of inequality in studies on trends in health inequalities [9].

A proper understanding of these trends requires an analysis of trends in inequalities in major determinants 
of mortality [5]. Smoking is often mentioned as the single most important mediating factor of inequalities in mortality. In line with the above-mentioned findings, we recently found a decline in absolute inequalities in smoking-attributable mortality, among men [10]. At the same time however, countries witnessed a substantial increase in obesity, and current socioeconomic inequalities in obesity across Europe suggest that the increase was larger among lower socioeconomic groups [11]. Elimination of socioeconomic inequalities in obesity might reduce inequalities in both mortality and morbidity substantially [12]; a widening of inequalities in obesity however, would buffer the impact of a decline of smoking attributable mortality on socioeconomic inequalities in mortality [13].

To better understand trends in socioeconomic inequalities in mortality, as well as to formulate hypotheses that help to identify the underlying causes of socioeconomic inequalities in obesity, it is important to compare trends in obesity-related disparities between countries [14]. Previous studies, mostly among residents of single nations, showed persistent or increasing socioeconomic inequalities in obesity in different countries [15-22]. One of the few international cross-country comparative trend studies, including 4 European countries, reported generally persistent social inequalities in obesity [23]. Studies on long-term changes in the prevalence of and inequalities in obesity across many European countries based on harmonized data sets are still scarce.

Acknowledging that Europe is a highly diverse world region known for health inequalities, the EU-funded "Developing methodologies to reduce inequalities in the determinants of health" project (DEMETRIQ) aimed to construct a harmonized dataset of health outcomes by indicators of socioeconomic position over the last decades [24]. The study offered the unique possibility to systematically assess the trends in socioeconomic inequalities in obesity in 15 European countries between 1990 and 2010.

\section{Methods}

\section{Data sources}

We obtained nationally representative health surveys from 15 European countries with more than two surveys available between the time period 1990 and 2010. Data came from the same survey over time for most of the countries, except for Austria, France, Hungary, and Italy (Table 1). The different data sources within these four countries have a high comparability [25-31], and thus could be included to analyze the trends over time. The age range used for all countries in the analysis was 3064 years. In Polish data information on age was provided in 10-year groups and thus for Poland the upper limit of
69 was used instead. Older respondents were excluded because the upper age limits differed between countries, which could have influenced the comparability of the level of inequalities in obesity. Younger respondents were excluded because many of them were still receiving full-time education and thus most likely represent a selective group with higher education. The number of included respondents per year ranged from 2238 (Finland in 1993) to 67,485 (Italy in 2005). For trends in education related inequalities, we included 15 countries with 60 country-year observations. To test the robustness of education as an indicator of socioeconomic position we performed sensitivity analysis analyzing inequality trends by occupational class, including 14 countries with 57 country-year observations.

\section{Variables}

To measure obesity, the body mass index (BMI) was calculated as weight in kilograms divided by square height in meters in all surveys. In 13 countries weight and height were self-reported, whereas in Ireland and Scotland weight and height were objectively measured. Obesity was defined as BMI $\geq 30 \mathrm{~kg} / \mathrm{m}^{2}$ [32].

Socioeconomic position was measured by educational level. Education levels were recorded as the highest level of education completed or currently being attended by a person. They were harmonized on the basis of the International Standard Classification of Education (ISCED) [33] and reclassified into 3 categories: levels $0-2$ (no, primary or lower secondary education, considered "low-educated"), levels 3-4 (upper secondary and post-secondary non-tertiary education, considered "middle-educated"), levels 5-6 (tertiary education, considered "high-educated").

Occupational classes were categorized as "manual" (considered the lower level) versus "non-manual" (considered the higher level). Respondents who were not economically active, and who could not be classified on the basis of their last or main occupation were classified as missing. Farmers and self-employed were excluded from the analysis. Since results are generally similar to those obtained for education, they will be presented in an online supplementary file.

\section{Statistical methods}

For each country, the prevalence rates of obesity were calculated by year, sex, and level of education, occupational class, and age-standardized to the European Standard Population using the direct standardization method [34]. For visual between-country comparison total prevalence rates and prevalence rates by socioeconomic group indicator were plotted as over time line charts.

Inequalities were measured by means of absolute prevalence rate differences (RD) and relative prevalence 
Table 1 List of countries and corresponding sources of data included in the analyses

\begin{tabular}{|c|c|c|c|c|c|}
\hline Country & Survey year & Survey name & Age range & $\begin{array}{l}\text { Number of respondents } \\
\text { (per year) }\end{array}$ & $\begin{array}{l}\text { Assessment of } \\
\text { weight and height }\end{array}$ \\
\hline \multirow[t]{2}{*}{ Austria } & 1991/1999 & Micro Census & $30-64$ & $21,867 \sim 22,557$ & Self-reported \\
\hline & 2006 & Health Interview Survey & $30-64$ & 8776 & Self-reported \\
\hline Belgium & 1997/2001/2004/2008 & Health Interview Survey & $30-64$ & $4874 \sim 5928$ & Self-reported \\
\hline Denmark & 1994/2000/2005/2010 & Danish Health and Morbidity Survey & $30-64$ & $2668 \sim 10,120$ & Self-reported \\
\hline Finland & $\begin{array}{l}\text { 1993/1995/1997/1999/ } \\
\text { 2001/2003/2005/2007/2009 }\end{array}$ & Health Behaviour and Health & $30-64$ & $2238 \sim 2599$ & Self-reported \\
\hline \multirow[t]{2}{*}{ France } & 1991-1992 & Enquête Décennale Santé & $30-64$ & 9619 & Self-reported \\
\hline & $2000 / 2005 / 2010$ & Baromètre santé & $30-64$ & $8108 \sim 17,281$ & Self-reported \\
\hline \multirow[t]{2}{*}{ Hungary } & 1994/2000/2003 & National Health Interview Survey & $30-64$ & $2997 \sim 4153$ & Self-reported \\
\hline & 2009 & European Health Interview Survey & $30-64$ & 3012 & Self-reported \\
\hline Ireland & 1998/2002/2007 & Survey of Lifestyle and Nutrition & $30-64$ & $3651 \sim 6488$ & Measured \\
\hline \multirow[t]{2}{*}{ Italy } & $1994 / 2000 / 2005$ & Health and Health Care Utilization & $30-64$ & $29,274 \sim 67,485$ & Self-reported \\
\hline & 1990/2010 & $\begin{array}{l}\text { Multipurpose Family Survey. Aspects } \\
\text { of Daily Living }\end{array}$ & $30-64$ & $24,190 \sim 31,318$ & Self-reported \\
\hline Netherlands & 1997/2000/2005/2009 & $\begin{array}{l}\text { Permanent Survey on Living } \\
\text { Conditions (POLS) }\end{array}$ & $30-64$ & $4064 \sim 5118$ & Self-reported \\
\hline Norway & 1998/2002/2005/2008 & Norwegian Level of living surveys & $30-64$ & $3990 \sim 4205$ & Self-reported \\
\hline Poland & 1996/2004/2009 & Polish Health Interview Survey & $30-69$ & $21,353 \sim 29,712$ & Self-reported \\
\hline Portugal & $\begin{array}{l}\text { 1995-1996/1998- } \\
1999 / 2005-2006\end{array}$ & National Health Survey & $30-64$ & $19,166 \sim 22,574$ & Self-reported \\
\hline Scotland & 1995/1998/2003 & Scottish Health Survey & $30-64$ & $5036 \sim 5997$ & Measured \\
\hline Spain & 1993/2001/2006 & National Health Survey & $30-64$ & $11,229 \sim 17,602$ & Self-reported \\
\hline Switzerland & 1992/1997/2002/2007 & Swiss Health Survey & $30-64$ & $6400 \sim 10,796$ & Self-reported \\
\hline
\end{tabular}

rate ratios (RR) of low versus high level of socioeconomic position. A bootstrap procedure with 1000 iterations was used to calculate $95 \%$ confidence intervals. Survey weights were available in some countries or years, but not in all. Thus, unweighted results are reported in the results section. A previous study based on the same data sources and with self-assessed health as the outcome found essentially similar results if weighted or unweigthed data were used [35].

To study the trends over time in each country and in the ensemble of countries as a whole, we employed meta-regression with random effects models, using the DerSimonian and Laird method [36]. The year of data collection was used as the only independent variable in the models and the total prevalence of obesity, the prevalence of obesity by level of socioeconomic position; the absolute (RD) and relative inequalities (RR) by socioeconomic position were included as the dependent variables. The country-specific regression parameters and their 95\% confidence intervals were displayed as forest plots and meta-analyses were performed to calculate overall random effect estimates for all countries. Data were analyzed for males and females separately. All analyses were performed using Stata/SE 13.1 (StataCorp, Texas, US).

\section{Results}

Time trends in obesity prevalence

The forest plots in Fig. 1a and b display the results of the meta-regression analysis for the trends in age-standardized obesity prevalence in 15 European countries between 1990 and 2010. An increase in the prevalence of obesity was found for almost all countries, but varied in magnitude between countries. In men, the pooled estimates for all countries indicated an increase of $0.33 \%$ points in the prevalence of obesity per year [95\% CI 0.26, 0.39]. Only in Ireland this increase was not statistically significant. The increase in the prevalence of obesity was particularly large in Scotland, Norway and Poland. In Switzerland, France and Italy, the overall increase was lower than the average increase across all countries included. In women, the pooled estimates for all countries indicated an increase of $0.28 \%$ points per year [95\% CI $0.19,0.36$ ] in the past two decades. In Poland, Hungary, France, Italy and Spain the increases were not statistically significant. Denmark, Scotland and Ireland witnessed an above average increase in the prevalence of obesity.

\section{Between-country comparison of changes in prevalence rates over time}

Figure 2 presents a graphical overview of the changes of obesity prevalence over time per country and by education. 

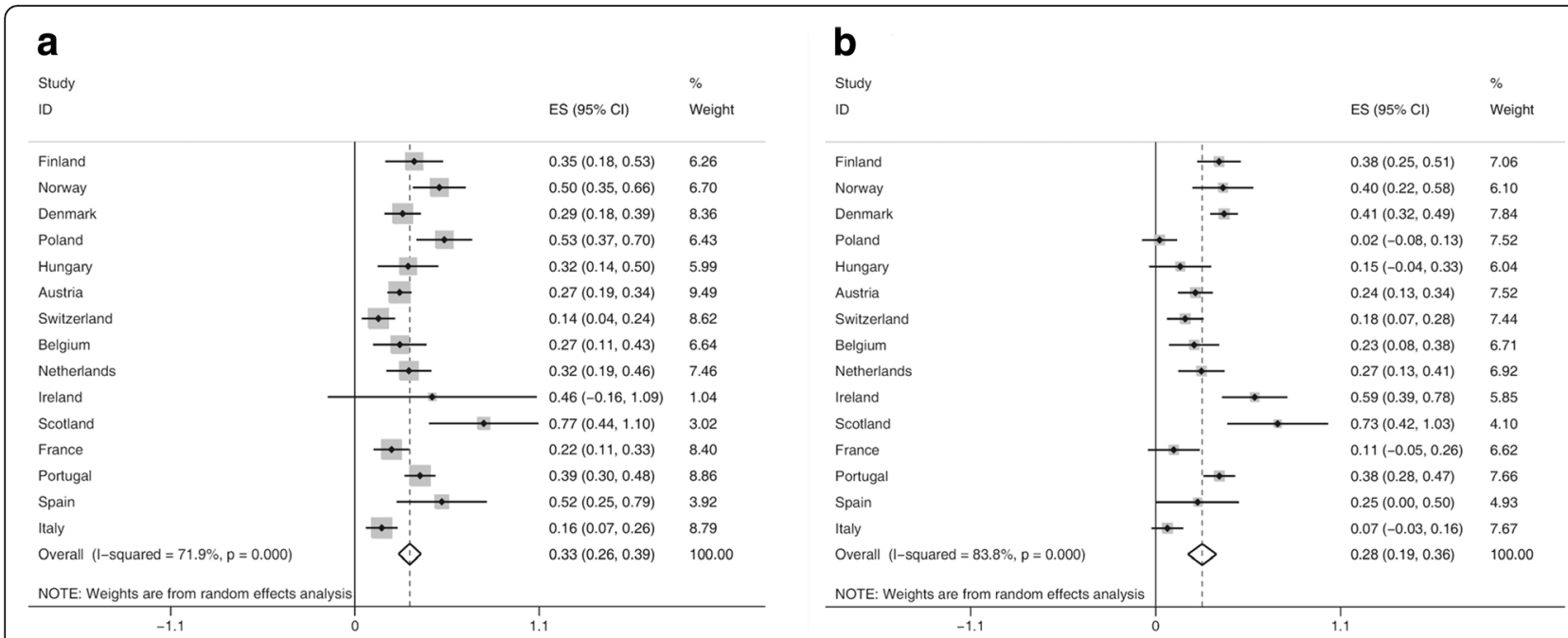

Fig. 1 Forest plot of meta-regression slopes for trends in prevalence of total obesity (BMI $\geq 30 \mathrm{~kg} / \mathrm{m}^{2}$ ) in (a) men and (b) women. ES, effect estimator (\% points change of obesity prevalence per year); $\mathrm{Cl}$, confidence interval

The prevalence rates in low, middle and high educational classes have increased over the past two decades in all 15 countries in both men (Fig. 2a) and women (Fig. 2b). Visual inspection of the graphs showed that obesity rates have been highest in low educated persons between 1990 and 2010, except in males in Hungary, Ireland and Poland (Fig. 2a). Even though the trends followed the same direction, the gaps between low and high educational groups differed in size and shape between the countries. Whereas in most of the countries the gaps in the prevalence of obesity between the educational levels seemed to remain relatively constant over time, a noticeable widening of the gap was particularly observed in Danish men (Fig. 2a).

\section{Time trends in absolute and relative inequalities in obesity prevalence}

The pooled estimates for all countries by educational level revealed a larger increase in obesity prevalence in the low educational group $(0.40 \%$ points per year [ $95 \%$ CI $0.30,0.49])$ as compared to the high educational group $(0.29 \%$ points per year [ $95 \%$ CI $0.20,0.39])$ in men [see Additional file 1: Figure S1a, b]. Country-specific estimates for the low educated group showed an increase in all countries (although not statistically significant in Hungary, Austria, Switzerland and Ireland). Increases were found as well in men in the high educational groups (although not statistically significant in Denmark, Hungary, Austria, Switzerland and Belgium), but they were generally smaller. In Finland, the Netherlands and Portugal, the increases were relatively similar between men in the low and high educational groups. A smaller increase in obesity prevalence in the low as compared to the high educational group was found in men in Ireland and Scotland. In women, the pooled estimates for all countries by educational level showed a larger increase in obesity in the low $(0.40 \%$ points per year [95\% CI 0.32, 0.49]) as compared to the high educated group $(0.25 \%$ points per year [ $95 \%$ CI 0.18 , 0.33]). [see Additional file 1: Figure S1c-d]. Among women in the low educational group, an increase in the prevalence of obesity was also observed in all countries (although not statistically significant in Finland, Switzerland and Ireland). They were generally larger than the increases in women in the high educational group. A smaller increase in obesity prevalence in women in the low as compared to the high educational group was found in Finland, Hungary, Austria, Ireland and Italy.

Meta-regressions of absolute educational inequalities in obesity resulted in a statistically significant overall increase in absolute inequalities of: $0.11 \%$ points [95\% CI $0.03,0.20]$ per year in men and $0.12 \%$ points $[95 \% \mathrm{CI}$ $0.04,0.20$ ] per year in women. No statistically significant trend was observed in the majority of the individual countries (Fig. 3a, b). The country-specific increase in absolute inequalities in obesity was only significant in Denmark in men (Fig. 3a) and in Belgium and France in women (Fig. 3b).

Figure $4 \mathrm{a}$ and $\mathrm{b}$ display the meta-regression results for the time trend of relative inequalities in obesity. The overall estimates pooled for all countries in men and women separately were slightly below 1 indicating that relative inequalities did not significantly change over time. In Austrian and Italian women a significant reduction of relative inequalities was found (Austria: 0.92 [95\% CI 0.86, 0.99]; Italy: 0.96 [95\% CI $0.94,0.99])$. 


\section{a}

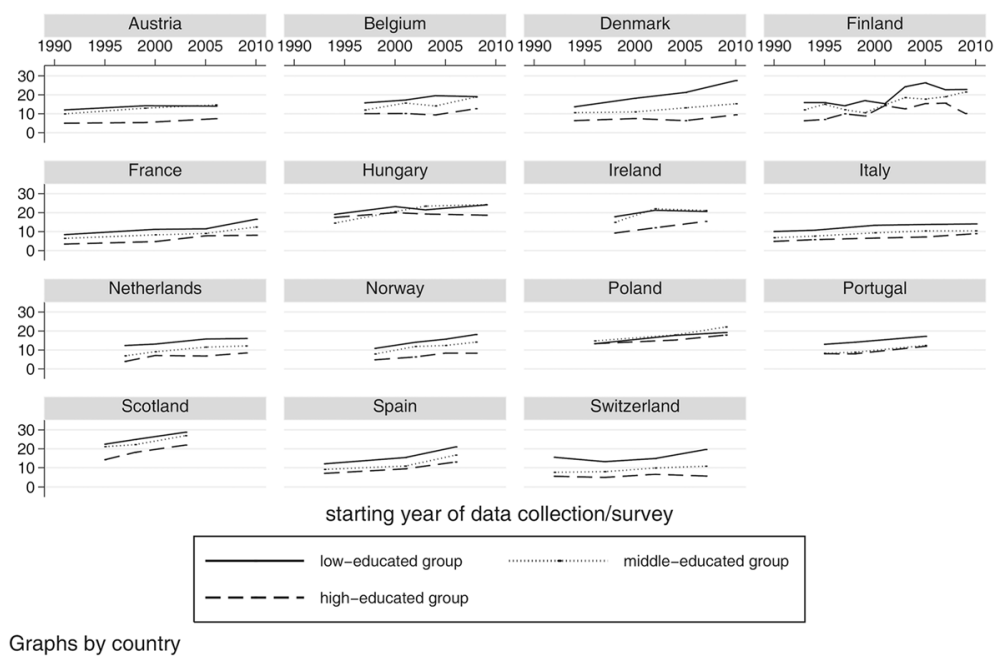

b

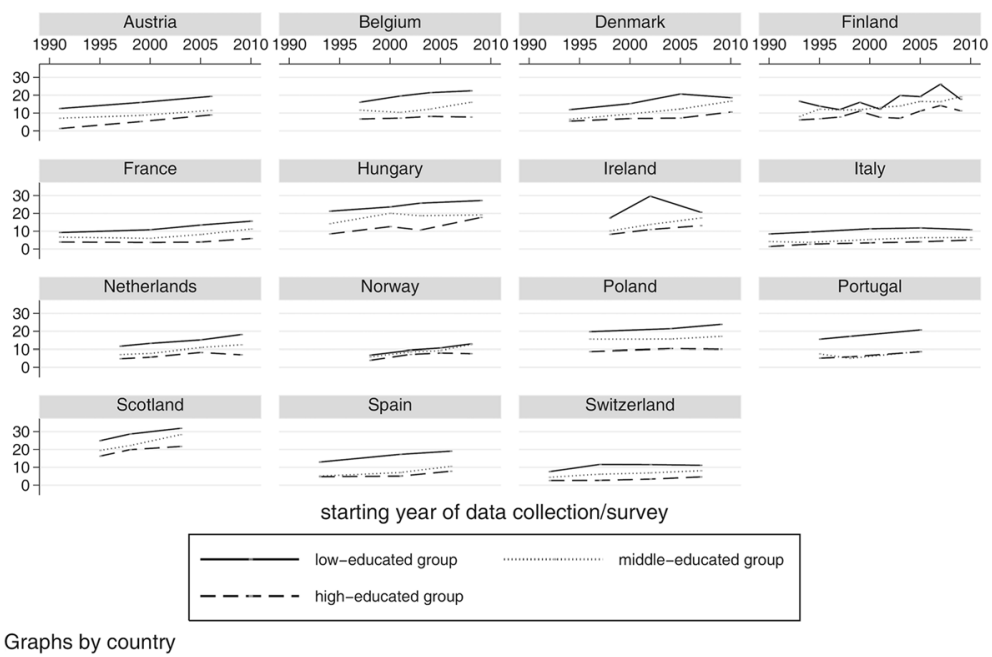

Fig. 2 Prevalence (\%) of obesity (BMI $\geq 30 \mathrm{~kg} / \mathrm{m}^{2}$ ) over time in (a) men and (b) women aged 30-64 in all countries stratified by educational level (ISCED 0-2, ISCED 3-4, ISCED 5-6)

\section{Discussion}

\section{Main findings}

Pooled analyses of data for 15 European countries showed an increase in the prevalence of obesity between 1990 and 2010 in both men and women. Increases in the prevalence were generally larger for those in the low as compared the high educated group. As a result, the pooled analysis showed an increase in absolute inequalities in obesity. At the country-level, this was statistically significant in Denmark in men and in Belgium and France in women. Relative inequalities were rather constant or slightly decreased between 1990 and 2010 .

\section{Strengths and limitations}

To the best of our knowledge, this study is the largest international comparison of time trends in socioeconomic inequalities in obesity across Europe, in terms of the number of countries and years included. Metaregression was used to systematically analyze trends in both absolute and relative inequalities in obesity. Efforts have been undertaken to overcome heterogeneity over time and between countries.

Measures of educational levels were harmonized by using the International Standard Classification of Education (ISCED) [33]. Whereas most countries used highest educational level completed, surveys in the Netherlands asked for 


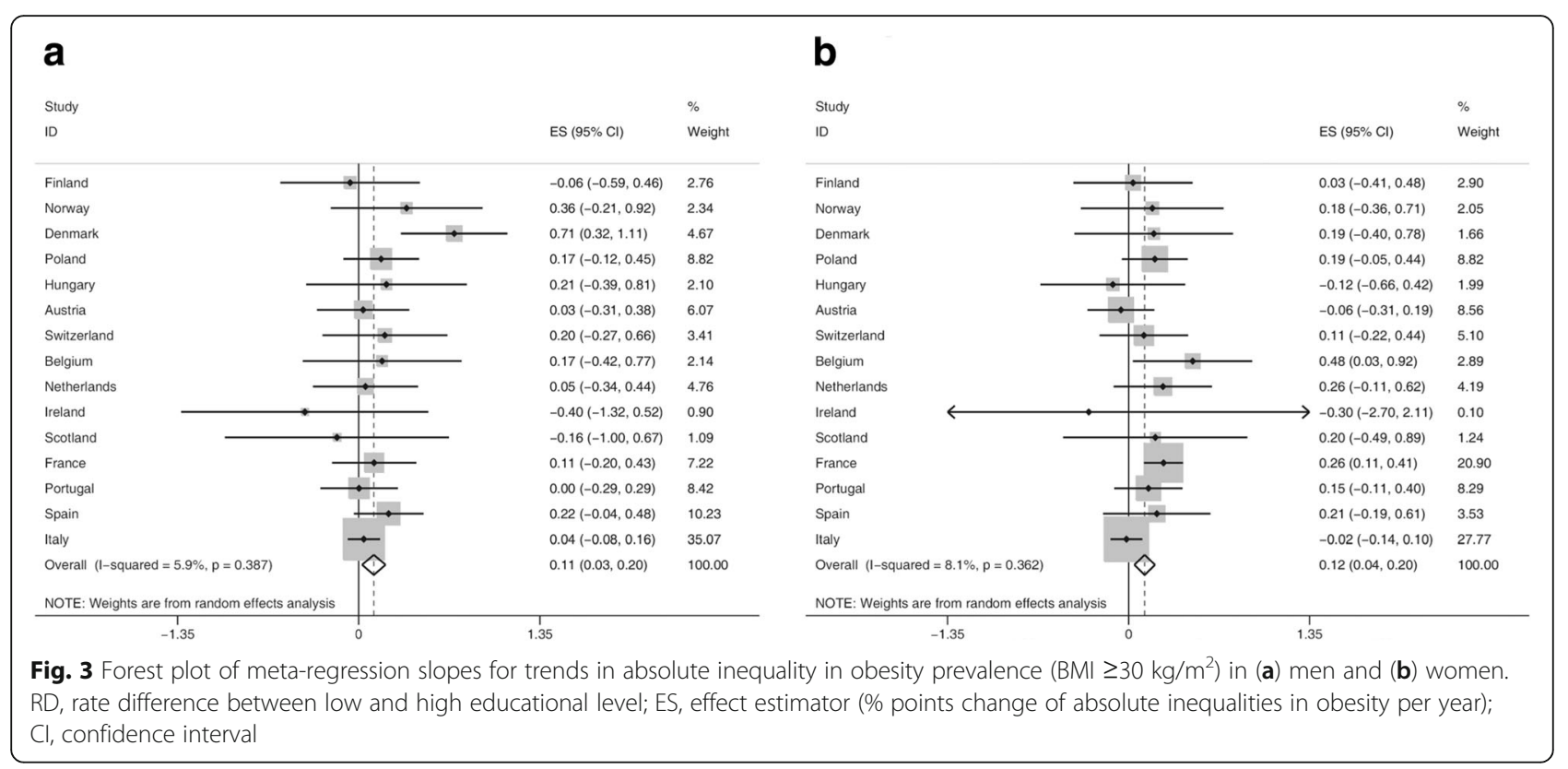

the highest level of education completed or attended. As a result, this might have generated larger proportions of persons in the middle and highest educational groups in the Netherlands as compared to the other countries. To the extent that obese persons more often did not complete the attended degree, educational gradients in obesity may have been underestimated in the Netherlands as compared to the other countries.

No single indicator however, captures the construct of socioeconomic position entirely. Other studies showed similar patterns of inequalities in obesity, measured by occupational status, income and educational level [15, 37, 38]. We also repeated the analyses for all countries using occupational class as an indicator of socioeconomic position from the same data sets, except for Portugal where no data on occupational position were available [see Additional file 2: Figure S2-S5]. Prevalence and inequality trends showed essentially similar patterns, thereby strengthening our findings for educational inequalities.

To facilitate the comparison between inequalities by different socioeconomic indicators, we used the RD and RR of low versus high education. However, these results might have been driven by changes in the distribution of educational level over time. For that reason we decided to repeat the analysis with indicators of inequalities that

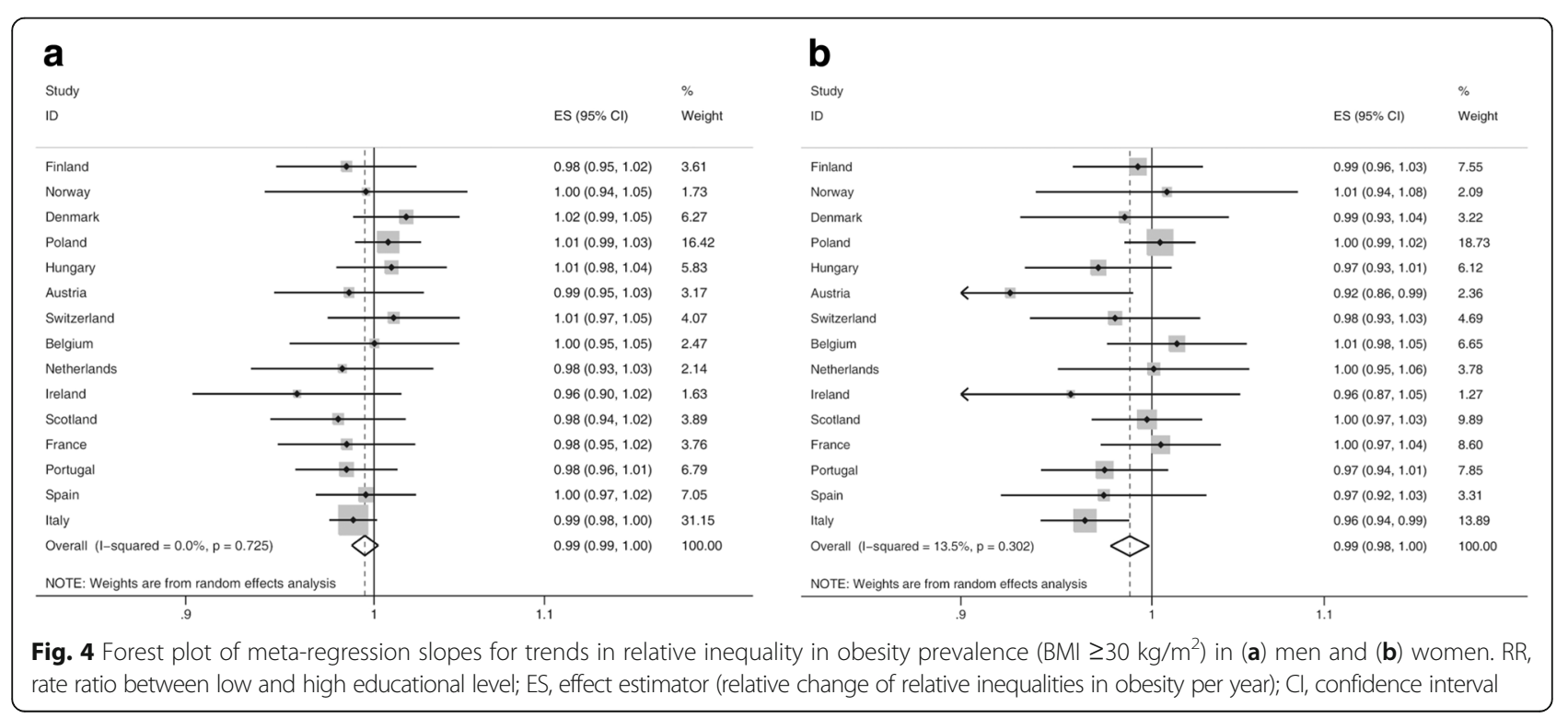


do take into account underlying distributions. We used the slope index of inequality (SII) and the relative index of inequality (RII) as an indicator for absolute and relative inequality, respectively. The SII in our analysis reflects the absolute difference in BMI between the least and the most advantaged individual, the RII can be interpreted as the relative risk of obesity for the least advantaged as compared to the most advantaged individual, both now taking into account the educational distribution by applying regression techniques [39].

The results were essentially similar. There was no discrepancy in significance of country-specific estimates of absolute inequalities measured by the RD and SII (see Additional file 3: Figure S6a, b). Only among women in Poland, we now found a significant increase in relative inequality measured by RII (see Additional file 3: Figure S7a, b).

Thus, these additional results support our main findings, e.g. an increase in absolute inequalities and stable relative inequalities between 1990 and 2010.

A potential limitation of our study concerned the assessment of BMI. In most of countries participants provided self-reported height and weight whereas in Ireland and Scotland these variables were measured. The heterogeneous nature of BMI assessment could have introduced potential bias in our analyses. It has been shown previously that obese people tend to underestimate their weight $[40,41]$. Whether there are differences in reporting between educational groups has not been clearly answered [42-44]. Nevertheless, Boström and Diderichsen found that reporting bias and its potential effect on inequalities in obesity are rather small due to the underestimation of BMI in all socioeconomic groups [45]. According to their findings, we might have underestimated inequalities in women and overestimated inequalities in men. Sensitivity meta-analysis of total obesity prevalence including only countries with self-reported BMI-assessment revealed no significant reduction of heterogeneity calculated by $\mathrm{I}^{2}$-statistics and no significant change in the estimates (data not shown).

Not having had access to the exact participation rates for each survey is another aspect of the data collection process, which might have affected our results in different ways. Firstly, response rates may have declined over time, and - to the extent the response rate was positively associated with levels of obesity - we may have underestimated increases in obesity over time. Secondly, participation rates may have differed between countries, and thirdly, participation may have differed between high and low socioeconomic groups. Particularly the latter may have affected the magnitude of inequalities.

Other data collection procedures may have had little impact on the analyses, to the extent that they did not change over time within countries.
It cannot be ruled out that our underlying assumption for the meta-analyses that trends in the outcome measures follow a linear pattern might not always hold true. However, this technique provides a systematic overview of the inequality trends in obesity within the last two decades in European countries. Whether non-linear trends might better fit the data was beyond the scope of this study but might be a helpful approach for future hypothesis-driven research.

\section{Comparison with other national and international studies}

Our finding of a significant increase in obesity among both men and women in Europe in the past two decades is in line with other trend studies [46-48]. A crosscountry comparative study showing that the largest increase in Europe occurred in the United Kingdom also aligns with our finding of the largest increase in obesity in Scotland over this time period [47]. Cross-country comparative trend studies on socioeconomic inequalities in obesity are scarce. A comparison of our findings with trend studies in single countries (France, Norway), however, confirmed the increase in the prevalence of obesity in lower and higher educated groups, although not unanimously $[18,21]$. One Swiss study reported a decline in absolute inequalities, due to a faster increase in the prevalence of obesity among higher educated [15]. The significant increase in absolute inequalities in Denmark among men is remarkable, especially as trends in social inequality for Denmark have not been reported before.

\section{Interpretation}

Obesity increased particularly in Scotland and in Scandinavia (in Norway among men, and in Denmark among women). For Scotland, reports suggested that societal changes and technological developments have created an obesogenic environment over time that impedes to maintain healthy weight $[49,50]$. Nordic countries are changing towards a less regulated marketliberalism potentially leading to an increased risk in obesity by a rise in fast-food industry in combination with a more stressful life [51]. While our findings on Scotland are in line with other studies, we were not able to find evidence why Scotland fared worse in the obesity epidemic. Indeed, major determinants of the change in obesity over time must be more prominent in Scotland than in other countries, but evidence which determinants these are is absent. For that reason we recommend to further expand cross-national comparative research on drivers of the obesity epidemic.

Apparently, the increase in obesity in almost all countries was not exclusive for either higher or lower socioeconomic groups. This finding further supports the notion that key determinants of obesity operate globally 
and affect entire populations. To the extent that the increase was larger for lower socioeconomic groups, the explanation must be that they were either more exposed to the underlying key determinants of obesity, or more vulnerable for such exposure. The rise in the prevalence has been attributed to societal and environmental changes resulting in obesogenic environments. Whereas initially differential exposure to obesogenic environment was thought to contribute to socioeconomic inequalities in obesity, Macintyre challenged the idea that lower socio-economic groups are more exposed to a food environment in which healthy food is less available and only at higher costs [52], a finding which has been empirically supported [53, 54]. Recent studies increasingly point towards social and cultural environments to explain the spread of obesity [55]. Such explanations for example suggest differences in cultural capital whereby healthy behaviors are used for the purpose of social distinction [56]. Whether and why lower socioeconomic groups are more vulnerable to obesogenic environments remains speculative.

One potential explanation is that resource scarcity (such as financial hardship) captures part of individuals' cognitive capacity - referred to as 'bandwidth' - in a way that it impedes health behavior and as such may interfere with decision making, long-term planning and increase risk taking" $[57,58]$.

Whereas absolute inequalities in obesity widened, no increase in relative inequalities was found. This finding must be interpreted against the background of the overall increase in obesity; in a situation of increasing prevalence rates, it requires a substantially larger increase in the lower than the higher socioeconomic groups to achieve a widening in relative inequalities.

As such, the patterns described in this study for obesity deviate markedly from those seen in smoking. Whereas the prevalence of smoking decreased in the past years, and because the decrease in smoking was more pronounced among higher socioeconomic groups, absolute inequalities tended to decline (particularly among men) and relative inequalities increased. According to the theory of fundamental causes of Link and Phelan [59], socioeconomic inequalities persist over time due to the persistence of inequalities in access to socioeconomic resources and due to the fact that elimination of one determinant will only result in its replacement by another factor. Translating this theory to our example, obesity may be in the process of taking over part of the role of smoking as a determinant of inequalities in health.

\section{Implications}

From a policy perspective, increasing prevalence rates and widening absolute inequalities are probably more relevant than widening relative inequalities. Thus, our findings further emphasizes the need for effective policies and interventions, with at least equal, but preferably larger effects among lower socioeconomic groups. For this purpose, Backholer et al. suggested that structural prevention strategies are likely to be more effective than approaches focusing on individual agents only, in which individuals are required to make independent choices [60]. Based on Backholer's framework, Olstad et al. systematically analyzed a more comprehensive set of obesity prevention policies. They suggested a rather neutral impact of the majority of the reviewed interventions in the agento-structural continuum on inequalities in obesity. However, in line with Backholer they confirmed that structural policies implemented at the macroenvironmental level might be more likely to positively impact inequalities [61]. Recent evidence on the impact of a tax on sugar-sweetened beverage, for example, is encouraging in terms of the reduction of the prevalence of obesity in general, and requires further evaluation with regard to its equity impact $[62,63]$.

\section{Conclusions}

The prevalence of obesity in European countries included in our study increased between 1990 and 2010, and more so in lower as compared to higher educational groups. As a result, absolute inequalities significantly increased between 1990 and 2010, whereas relative inequalities persisted or slightly declined. Our findings urge for a further understanding of the drivers of the increase in obesity in lower education groups, and an equity perspective in population-based obesity prevention strategies.

\section{Additional files}

Additional file 1: Contains the results for trends in obesity prevalence for the low- and high-educated groups separately. The analysis was performed according to the method section described in the main manuscript. (PDF $219 \mathrm{~kb}$ )

Additional file 2: Contains the results for trends in obesity prevalence and occupation-related inequalities in obesity for both men and women. All analyses were performed according to the method section described in the main manuscript. (PDF $332 \mathrm{~kb}$ )

Additional file 3: Contains the results for education-related trends in slope index of inequality and relative index of inequality for obesity for both men and women. All analyses were performed according to the method section described in the main manuscript. (PDF $224 \mathrm{~kb}$ )

\section{Abbreviations}

BMI: Body mass index; Cl: Confidence interval; EU: European union; GDP: Gross domestic product; ISCED: International standard classification of education; OECD: Organization for economic co-operation and development; RD: Rate difference; RR: Rate ratio

\section{Acknowledgements}

The author thanks the DEMETRIQ study group for the permission to use of the data. 
The authors thank Stefaan Demarest (Scientific Institute of Public Health, Belgium), Satu Helakorpi and Anni Helldàn (both Finnish National Institute for Health and Welfare THL, Finland), Eszter Balku (National Institute for Health Development, Hungary) for providing data, and Catherin Bosle (Mannheim Institute of Public Health, Germany) for organizational assistance in preparing this manuscript.

\section{Funding}

This study has been supported by a grant from the European Union under the FP7 Health program funding the "Developing methodologies to reduce inequalities in the determinants of health" project DEMETRIQ, grant agreement no. 278511.

\section{Availability of data and materials}

The statistical agencies which supplied the survey data have not given us permission for further dissemination of the underlying micro-data.

\section{Authors' contributions}

JPM and FJVL had the original idea for the study. RDG, YH, MP, VJ, EL, GM, PS, ER and OE made substantial contributions to the data acquisition. KH performed the data analysis. RdG and YH supported the analysis of the data. $\mathrm{KH}$, FJVL and JPM substantially contributed to the drafting of the manuscript. All the authors contributed to the interpretation of the results, and reviewed and approved the final manuscript.

\section{Competing interests}

The authors declare that they have no competing interests.

\section{Consent for publication}

Not applicable.

\section{Ethics approval and consent to participate}

Not applicable.

\section{Publisher's Note}

Springer Nature remains neutral with regard to jurisdictional claims in published maps and institutional affiliations.

\section{Author details}

'Department of Public Health, Erasmus MC, University Medical Center Rotterdam, P.O. Box 2040, 3000 CA Rotterdam, Netherlands. ${ }^{2}$ Mannheim Institute of Public Health, Social and Preventive Medicine, Medical Faculty Mannheim, Heidelberg University, Mannheim, Germany. ${ }^{3}$ Epidemiology, Biostatistics and Prevention Institute, University of Zürich, Zürich, Switzerland. ${ }^{4}$ National Institute for Health Development, Budapest, Hungary. ${ }^{5}$ Department of Public Health, University of Helsinki, Helsinki, Finland. ${ }^{6}$ Sorbonne Universités, INSERM, Institut Pierre Louis d'Epidémiologie et de Santé Publique (IPLESP UMRS 1136), Paris, France. 7 Departamento de Geografia, Centro de Estudos de Geografia e de Ordenamento do Territorio (CEGOT), Colégio de S. Jerónimo, Universidade de Coimbra, Coimbra, Portugal. ${ }^{8}$ Department of Preventive Medicine and Public Health, Universidad Complutense de Madrid, Madrid, Spain. ${ }^{9}$ National Institute of Public Health, University of Southern Denmark, Copenhagen, Denmark.

Received: 1 October 2016 Accepted: 22 April 2017

Published online: 08 May 2017

\section{References}

1. Pamuk ER. Social class inequality in mortality from 1921 to 1972 in England and Wales. Popul Stud. 1985:39:17-31.

2. Cavelaars AE, Kunst AE, Geurts JJ, Crialesi R, Grotvedt L, Helmert U, et al. Differences in self reported morbidity by educational level: a comparison of 11 western European countries. J Epidemiol Community Health. 1998;52: 219-27.

3. Mackenbach JP, Huisman M, Andersen O, Bopp M, Borgan JK, Borrell C, et al. Inequalities in lung cancer mortality by the educational level in 10 European populations. Eur J Cancer. 2004;40:126-35.

4. Huisman M, Kunst AE, Bopp M, Borgan JK, Borrell C, Costa G, et al. Educational inequalities in cause-specific mortality in middle-aged and older men and women in eight western European populations. Lancet. 2005;365:493-500.
5. Mackenbach JP, Stirbu I, Roskam AJ, Schaap MM, Menvielle G, Leinsalu M, et al. Socioeconomic inequalities in health in 22 European countries. N Engl J Med. 2008;358:2468-81.

6. Leinsalu M, Stirbu I, Vågerö D, Kalediene R, Kovacs K, Wojtyniak B, et al. Educational inequalities in mortality in four eastern European countries: divergence in trends during the post-communist transition from 1990 to 2000. Int J Epidemiol. 2009;38:512-25.

7. Gallo V, Mackenbach JP, Ezzati M, Menvielle G, Kunst AE, Rohrmann S, et al. Social inequalities and mortality in Europe-results from a large multi-national cohort. PLoS One. 2012;7:e39013.

8. Mackenbach JP, Kulhanova I, Artnik B, Bopp M, Borrell C, Clemens T, et al. Changes in mortality inequalities over two decades: register based study of European countries. BMJ. 2016:353:11732.

9. Moonesinghe R, Beckles GL. Measuring health disparities: a comparison of absolute and relative disparities. PeerJ. 2015:3:e1438.

10. Gregoraci G, van Lenthe FJ, Artnik B, Bopp M, Deboosere P, Kovacs K, et al. Contribution of smoking to socioeconomic inequalities in mortality: a study of 14 European countries, 1990-2004. Tob Control. 2017;26(3):260-8.

11. Roskam AJ, Kunst AE, Van Oyen H, Demarest S, Klumbiene J, Regidor E, et al. Comparative appraisal of educational inequalities in overweight and obesity among adults in 19 European countries. Int J Epidemiol. 2010;39:392-404.

12. Hoffmann R, Eikemo TA, Kulhanova I, Kulik MC, Looman C, Menvielle G, et al. Obesity and the potential reduction of social inequalities in mortality: evidence from 21 European populations. Eur J Pub Health. 2015;25(5):849-56.

13. Mackenbach JP. What would happen to health inequalities if smoking were eliminated? BMJ. 2011;342:d3460

14. World Health Organization. Obesity: Preventing and managing the global epidemic. 2000. http://www.who.int/nutrition/publications/obesity/WHO_ TRS_894/en/. Accessed 3 May 2017.

15. Galobardes B, Costanza MC, Bernstein MS, Delhumeau C, Morabia A. Trends in risk factors for lifestyle-related diseases by socioeconomic position in Geneva, Switzerland, 1993-2000: health inequalities persist. Am J Public Health. 2003;93:1302-9.

16. Pikhart H, Bobak M, Malyutina S, Pajak A, Kubinova R, Marmot M. Obesity and education in three countries of the central and Eastern Europe: the HAPIEE study. Cent Eur J Public Health. 2007:15:140-2.

17. Garcia-Alvarez A, Serra-Majem L, Ribas-Barba L, Castell C, Foz M, Uauy R, et al. Obesity and overweight trends in Catalonia, Spain (1992-2003): gender and socio-economic determinants. Public Health Nutr. 2007;10:1368-78.

18. Singh-Manoux A, Gourmelen J, Lajnef M, Sabia S, Sitta R, Menvielle G, et al. Prevalence of educational inequalities in obesity between 1970 and 2003 in France. Obes Rev. 2009;10:511-8.

19. Stamatakis E, Wardle J, Cole TJ. Childhood obesity and overweight prevalence trends in England: evidence for growing socioeconomic disparities. Int J Obes. 2010;34:41-7.

20. Gallus S, Odone A, Lugo A, Bosetti C, Colombo P, Zuccaro P, et al. Overweight and obesity prevalence and determinants in Italy: an update to 2010. Eur J Nutr. 2013;52:677-85.

21. Krokstad S, Ernstsen L, Sund ER, Björngaard JH, Langhammer A, Midthjell K, et al. Social and spatial patterns of obesity diffusion over three decades in a Norwegian county population: the HUNT study. BMC Public Health. 2013;13:973.

22. Alaba O, Chola L. Socioeconomic inequalities in adult obesity prevalence in South Africa: a decomposition analysis. Int J Environ Res Public Health. 2014; 11:3387-406.

23. Devaux M, Sassi F. Social inequalities in obesity and overweight in $11 \mathrm{OECD}$ countries. Eur J Pub Health. 2013;23:464-9.

24. Demetriq. Developing methodologies to reduce inequalities in the determinants of health (DEMETRIQ). http://www.demetriq.eu/. Accessed 3 May 2017.

25. Grossschadl F, Stronegger WJ. Long-term trends in obesity among Austrian adults and its relation with the social gradient: 1973-2007. Eur J Pub Health. 2013:23:306-12.

26. Mormiche P. L'Enquête Décennale sur la Santé 1991-1992. Bilan de la réalisation et des apports. In: Courrier des statistiques. Institut national de la statistique et des études économiques 1996. http://www.youscribe.com/ catalogue/documents/ressources-professionnelles/l-enquete-decennale-surla-sante-1991-1992-bilan-de-la-realisation-1960946. Accessed 3 May 2017.

27. Institut national de prévention et d'éducation pour la santé. Baromètres santé http://www.inpes.sante.fr/Barometres/index.asp. Accessed 3 May 2017.

28. Hungarian Central Statistical Office. European Health Interview Survey (EHIS), 2009. In: Statistical reflection. KSH. 2010. http://www.ksh.hu/docs/eng/xttp/ stattukor/eelef09.pdf. Accessed 3 May 2017. 
29. Remak E, Gal R, Nemeth R. Health and morbidity in hungary. In: ENEPRI Research Report. European Network of Economic Policy Research Institutes. 2007. http://aei.pitt.edu/9437/2/9437.pdf. Accessed 3 May 2017.

30. Italian National Institute of Statistics (ISTAT). Multipurpose survey on households: aspects of daily life. http://siqual.istat.it/SIQual/visualizza.do?id=0058000. Accessed 3 May 2017.

31. Italian National Institute of Statistics (ISTAT). Condizioni di salute e ricorso ai servizi sanitari [Health and Health Care Utilization]. http://www.istat.it/it/ archivio/5471. Accessed 3 May 2017.

32. World Health Organization. WHO Global data base on body mass index: BMI classification 2009. http://www.euro.who.int/en/health-topics/diseaseprevention/nutrition/a-healthy-lifestyle/body-mass-index-bmi. Accessed 3 May 2017.

33. UNESCO Institute for Statistic. International Standard Classification of Education (ISCED 1997). 1997. http://www.unesco.org/education/information/nfsunesco/ doc/isced_1997.htm. Accessed 3 May 2017.

34. Ahmad O, Boschi-Pinto C, Lopez A, Murray C, Lonzano R, Inoue M. Age Standardization of Rates: a New WHO Standard. In: GPE Discussion Paper Series: No.31. World Health Organization. 2001. http://www.who.int/healthinfo/ paper31.pdf. Accessed 3 May 2017.

35. Hu Y, van Lenthe FJ, Borsboom GJ, Looman CW, Bopp M, Burström B, et al. Trends in socioeconomic inequalities in self-assessed health in 17 European countries between 1990 and 2010. J Epidemiol Community Health. 2016;70: 644-52.

36. DerSimonian R, Laird N. Meta-analysis in clinical trials. Control Clin Trials. 1986;7:177-88

37. Faeh D, Braun J, Bopp M. Prevalence of obesity in Switzerland 1992-2007: the impact of education, income and occupational class. Obes Rev. 2011;12: 151-66.

38. Prättälä R, Sippola R, Lahti-Koski M, Laaksonen MT, Mäkinen T, Roos E. Twentyfive year trends in body mass index by education and income in Finland. BMC Public Health. 2012:12:8

39. Mackenbach JP, Kunst AE. Measuring the magnitude of socio-economic inequalities in health: an overview of available measures illustrated with two examples from Europe. Soc Sci Med. 1997;44:757-71.

40. Ziebland S, Thorogood M, Fuller A, Muir J. Desire for the body normal: body image and discrepancies between self reported and measured height and weight in a British population. J Epidemiol Community Health. 1996;50:105-6.

41. Shields M, Connor Gorber S, Tremblay MS. Estimates of obesity based on self-report versus direct measures. Health Rep. 2008;19:61-76.

42. Jalkanen L, Tuomilehto J, Tanskanen A, Puska P. Accuracy of self-reported body weight compared to measured body weight. A population survey. Scand J Soc Med. 1987;15:191-8.

43. Rowland ML. Self-reported weight and height. Am J Clin Nutr. 1990;52:1125-33.

44. Niedhammer I, Bugel I, Bonenfant S, Goldberg M, Leclerc A. Validity of selfreported weight and height in the French GAZEL cohort. Int J Obes Relat Metab Disord. 2000;24:1111-8.

45. Boström G, Diderichsen F. Socioeconomic differentials in misclassification of height, weight and body mass index based on questionnaire data. Int J Epidemiol. 1997;26:860-6.

46. Finucane MM, Stevens GA, Cowan MJ, Danaei G, Lin JK, Paciorek CJ, et al. National, regional, and global trends in body-mass index since 1980: systematic analysis of health examination surveys and epidemiological studies with 960 country-years and 9.1 million participants. Lancet. 2011;377:557-67.

47. Stevens GA, Singh GM, Lu Y, Danaei G, Lin JK, Finucane MM, et al. National, regional, and global trends in adult overweight and obesity prevalences. Popul Health Metr. 2012:10:22.

48. Collaboration NCDRF. Trends in adult body-mass index in 200 countries from 1975 to 2014: a pooled analysis of 1698 population-based measurement studies with 19.2 million participants. Lancet. 2016;387:1377-96.

49. Butland B, Jebb S, Kopelman P, McPherson K, Thomas S, Mardell J, et al. Tackling Obesities: Future Choices Project report, 2nd ed. 2007. https://www.gov. uk/government/uploads/system/uploads/attachment_data/file/287937/07-1184xtackling-obesities-future-choices-report.pdf. Accessed 3 May 2017.

50. Scottish G. The Scottish Health Survey. 2011. http://www.gov.scot/Resource/ 0038/00389668.pdf. Accessed 3 May 2017.

51. Magnusson M, Sørensen TI, Olafsdottir S, Lehtinen-Jacks S, Holmen TL, Heitmann BL, et al. Social inequalities in obesity persist in the Nordic region despite its relative affluence and equity. Curr Obes Rep. 2014;3:1-15.
52. Macintyre S. Deprivation amplification revisited; or, is it always true that poorer places have poorer access to resources for healthy diets and physical activity? Int J Behav Nutr Phys Act. 2007:4:32.

53. Giskes K, van Lenthe F, Avendano-Pabon M, Brug J. A systematic review of environmental factors and obesogenic dietary intakes among adults: are we getting closer to understanding obesogenic environments? Obes Rev. 2011; 12:e95-e106.

54. Cummins S, Macintyre S. Food environments and obesity-neighbourhood or nation? Int J Epidemiol. 2006:35:100-4.

55. Christakis NA, Fowler JH. The spread of obesity in a large social network over 32 years. N Engl J Med. 2007;357:370-9.

56. Abel T. Cultural capital and social inequality in health. J Epidemiol Community Health. 2008;62:e13.

57. Mani A, Mullainathan S, Shafir E, Zhao J. Poverty impedes cognitive function. Science. 2013;341:976-80.

58. Truesdale $B C$, Jencks $C$. The health effects of income inequality: averages and disparities. Annu Rev Public Health. 2016;37:413-30.

59. Link BG, Phelan J. Social conditions as fundamental causes of disease. J Health Soc Behav. 1995;Spec No:80-94.

60. Backholer K, Beauchamp A, Ball K, Turrell G, Martin J, Woods J, et al. A framework for evaluating the impact of obesity prevention strategies on socioeconomic inequalities in weight. Am J Public Health. 2014;104:e43-50.

61. Olstad DL, Teychenne M, Minaker LM, Taber DR, Raine KD, Nykiforuk Cl, et al. Can policy ameliorate socioeconomic inequities in obesity and obesity-related behaviours? A systematic review of the impact of universal policies on adults and children. Obes Rev. 2016;17:1198-217.

62. Briggs ADM, Mytton OT, Kehlbacher A, Tiffin R, Rayner M, Scarborough P. Overall and income specific effect on prevalence of overweight and obesity of $20 \%$ sugar sweetened drink tax in UK: econometric and comparative risk assessment modelling study. BMJ. 2013;347:f6189.

63. Colchero MA, Popkin BM, Rivera JA, Ng SW. Beverage purchases from stores in Mexico under the excise tax on sugar sweetened beverages: observational study. BMJ. 2016:352:h6704.

\section{Submit your next manuscript to BioMed Central and we will help you at every step:}

- We accept pre-submission inquiries

- Our selector tool helps you to find the most relevant journal

- We provide round the clock customer support

- Convenient online submission

- Thorough peer review

- Inclusion in PubMed and all major indexing services

- Maximum visibility for your research

Submit your manuscript at www.biomedcentral.com/submit 